\title{
More beef calves from the dairy industry: a survey
}

\author{
L. OLIVER and A. MCDERMOTT \\ AgResearch, Ruakura Research Centre, PB 3123, Hamilton \\ alan.mcdermott@agresearch.co.nz
}

\begin{abstract}
A telephone survey of dairy farmers, calf rearing farmers, and finishing farmers was undertaken to discover opinions regarding dairy-beef cattle and the barriers to increasing the quality and quantity of dairy-beef cattle produced by the dairy industry. A total of 158 farmers were surveyed from throughout New Zealand. Dairy farmers make the most critical decisions regarding the genetic make-up of most cattle entering the NZ beef industry. To ensure these decisions benefit the beef industry, there is a need for incentives to encourage dairy farmers to use more beef genetics across their herds. The survey results suggest a premium for dairy-beef calves of $\$ 30-\$ 50 /$ calf above Friesian bull calf prices would be an adequate incentive. Delivering this premium requires a co-ordinated effort involving beef finishers, calf rearers, dairy farmers and beef processors.
\end{abstract}

Keywords: beef finishers, calf rearers, dairy-beef cattle, dairy farmers, incentives, industry co-ordination

\section{Introduction}

Sixty-five percent of NZ's beef by volume is sourced either directly (cull cows and bobby calves) or indirectly (bull beef and dairy-beef cross) from the dairy sector (Beeby 2003). This high proportion of supply from the dairy sector is raising industry-wide concerns about the alignment of the "beef" herd to current and developing table cut markets. Processors are finding it increasingly difficult to source traditional beef-type animals to supply the domestic and export markets for table cuts of beef.

Earlier research using the Beef Value Chain Model demonstrated that by doubling the use of beef sires in the dairy industry from approximately $19 \%$ to $29 \%$ of progeny, the net benefit to NZ beef industry would be $\$ 57$ million per annum (McDermott et al. 2005). This additional value could be shared among all of the participants along the dairy-beef value chain.

This paper highlights the findings from three telephone surveys of dairy, calf rearing and beef finishing farmers randomly selected from throughout NZ. The objective of this project was to determine the profitability, feasibility, risks and constraints associated with using beef sires in dairy herds from the perspective of these three groups.

\section{Method}

Semi-structured interviews were conducted with 20 dairy farmers, 10 calf-rearing farmers and 10 cattle finishing farmers to get an overview of the issues involved in using beef sires in dairy herds. This information was then used to construct telephone surveys for dairy farmers, calf rearers and beef finishers. A mentor group that included beef breeders, dairy farmers, calf rearers, beef finishers and processors was convened to discuss the findings from the interviews, review the design of the survey and identify any other important issues for increasing the use of beef sires across dairy herds.

The telephone interviews occurred in July 2004 across a random sample of farmers throughout NZ.

- Dairy farmers - 91 successful telephone interviews. Average herd size 342 cows.

- Calf rearing farmers - 23 successful telephone interviews. Median number of calves reared 213.

- Beef finishers - 44 successful telephone interviews. Eighty percent of respondents finished more than 50 cattle/yr.

The data from the three surveys was analysed using the SAS ${ }^{\text {TM }}$ statistics software. Key results are presented in the results section. The main analysis focused on current practices, farmers' beliefs about fair premiums and the level of importance placed on, and satisfaction farmers feel about, different aspects of their business.

\section{Results}

\section{Dairy farmer survey}

Beef semen for artificial insemination

Sixty-four percent of respondents did not use any beef semen for artificial insemination, and only $7 \%$ of respondents inseminated $10 \%$ or more of their herd with beef semen. Herd size had no bearing on the propensity of farmers to use beef semen. Low production, low breeding worth (BW) and late cycling were the most commonly cited reasons for artificially inseminating a cow with beef semen. Breed and calving ease were the most commonly used criteria for selection of a beef semen sire. Interestingly, price was not often cited as a selection criterion. There is a perception among $70 \%$ of respondents that beef semen will cause a greater incidence of calving difficulty than dairy semen.

\section{Beef sires for natural mating}

Twenty-four percent of respondents did not use any beef bulls to mate their herd (Figure 1). Sixty-four percent of 
Figure 1 Percentage of herd mated to beef bulls by respondents to the dairy farmer survey, $n=91$.

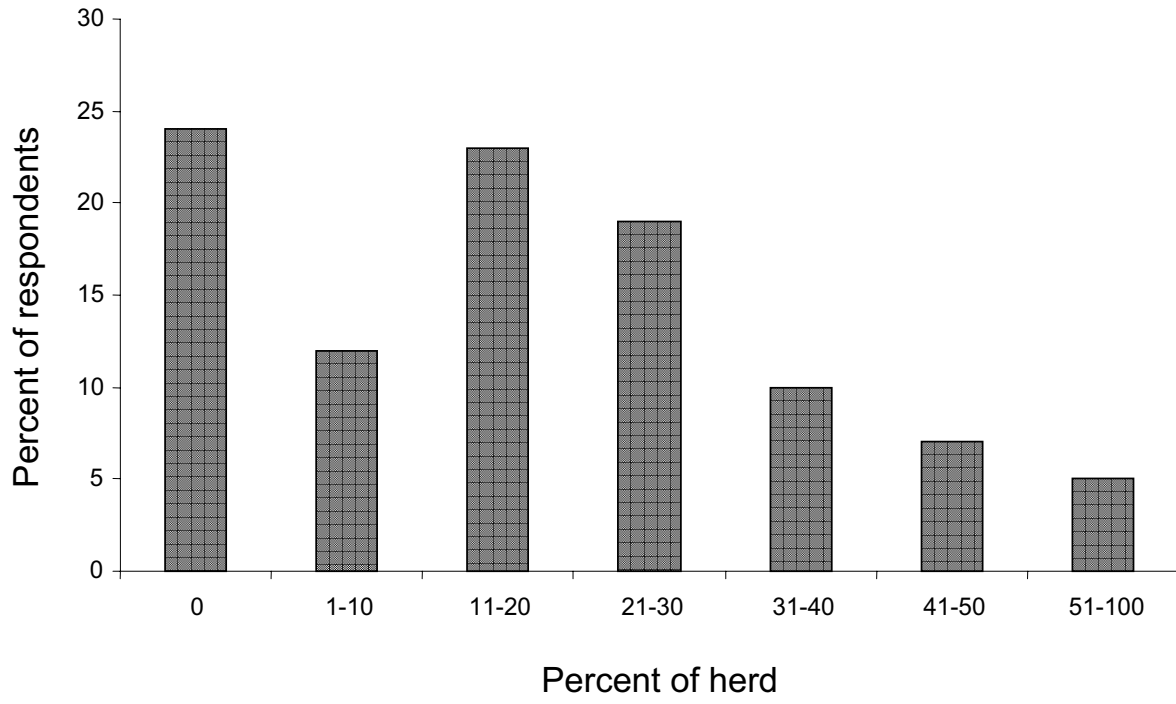

Table 1 Level of importance dairy farmers place on factors related to mating and calf sales.

\begin{tabular}{lccc}
\hline Question & Mean & SD & n \\
\hline Ease of calving & 9.3 & 1.4 & 91 \\
Payment security for calves & 8.7 & 1.7 & 87 \\
Producing a sufficient no. of herd replacements & 8.7 & 2.0 & 91 \\
Minimising the total cost of mating & 8.3 & 2.1 & 91 \\
The certainty that you can sell your calves when you want to & 8.1 & 1.8 & 88 \\
Using beef sires that are performance recorded for calving ease & 8.1 & 2.4 & 90 \\
Having a long-term relationship with calf buyers & 7.6 & 2.2 & 84 \\
The price you receive for your calves & 6.8 & 2.3 & 88 \\
Receiving a premium for dairy-beef calves & 6.5 & 2.4 & 82 \\
Being able to buy bulls that will produce calves with a high growth rate & 5.8 & 2.7 & 89 \\
Mating your herd to short gestation bulls & 5.7 & 2.6 & 91 \\
Having a binding contract with a calf buyer & 81 \\
\hline
\end{tabular}

respondents mated at least $10 \%$ of their herd to beef bulls. Breed and calving ease were the most common criteria used to select beef bulls. However, price and past experience were also prominent and unfortunately some farmers use no selection criterion. Some dairy farmers were using breed to ensure a clear colour change in the progeny of their herd as an identifier of non-dairy replacements.

Seventy percent of survey respondents indicated that they would use beef semen in preference to unrecorded beef bulls for a premium of $\$ 30 /$ hd on the resulting 4day old calves. The response rate for this question (32/ 91) was much lower than for other questions, so caution must be taken when interpreting the results in case the sample has been biased in some way. One factor acting against the introduction of beef genetics through $\mathrm{AI}$ is that $80 \%$ of respondents indicated that they prefer natural beef mating over AI.
The premium received for Friesian bull calves over bobby calf ${ }^{1}$ price ranged from $\$ 0-170$ per head (average $=\$ 52$ per head). The average price received was $\$ 9 / \mathrm{hd}$ less than what respondents regarded as a fair price $(\mathrm{P}<0.01)$. The premium received for beef-cross bull calves over Friesian bull calves ranged from $\$ 0-200 /$ hd (average $=\$ 31$ per head). The average price received was $\$ 8 / \mathrm{hd}$ less than what respondents regarded as a fair price $(\mathrm{P}<0.01)$. Forty-two percent of respondents said that they received no premium for beef-cross bull calves over Friesian bull calves and $23 \%$ believed that this was fair. The premium received for dairy-beef bull calves over dairy-beef heifer calves ranged from $\$ 0$-100 per head (average $=\$ 31$ per head). There was no significant difference between the average premium received and what respondents regarded a fair premium.

Respondents were asked to rate a series of factors relating to herd mating and calf sales on a scale of 1-10

${ }_{1}^{1}$ Bobby calves being those sold for slaughter as opposed to those sold to calf rearers. 
Table 2 Level of satisfaction dairy farmers have with factors relating to mating and calf sales.

\begin{tabular}{lccc}
\hline Question & Mean & SD & n \\
\hline Payment security offered by your main calf buyer & 8.0 & 2.0 & 83 \\
Ease of calving in your herd & 7.8 & 1.6 & 91 \\
That you are producing a sufficient no. of herd replacements & 7.6 & 2.0 & 89 \\
Long-term relationships you have with calf buyers & 7.4 & 1.9 & 79 \\
That you can sell your calves with certainty when you want to & 6.4 & 2.0 & 88 \\
Gestation length of your current bulls & 6.7 & 2.9 & 91 \\
Premium you receive for your dairy-beef calves & 6.3 & 2.3 & 72 \\
Your current mating costs & 6.1 & 2.5 & 80 \\
Availability of beef sires that are performance recorded for calving ease & & 81 \\
\hline
\end{tabular}

Figure 2 Current and preferred proportions of dairy-beef calves reared by respondents to the calf rearer survey, $\mathrm{n}=23$.

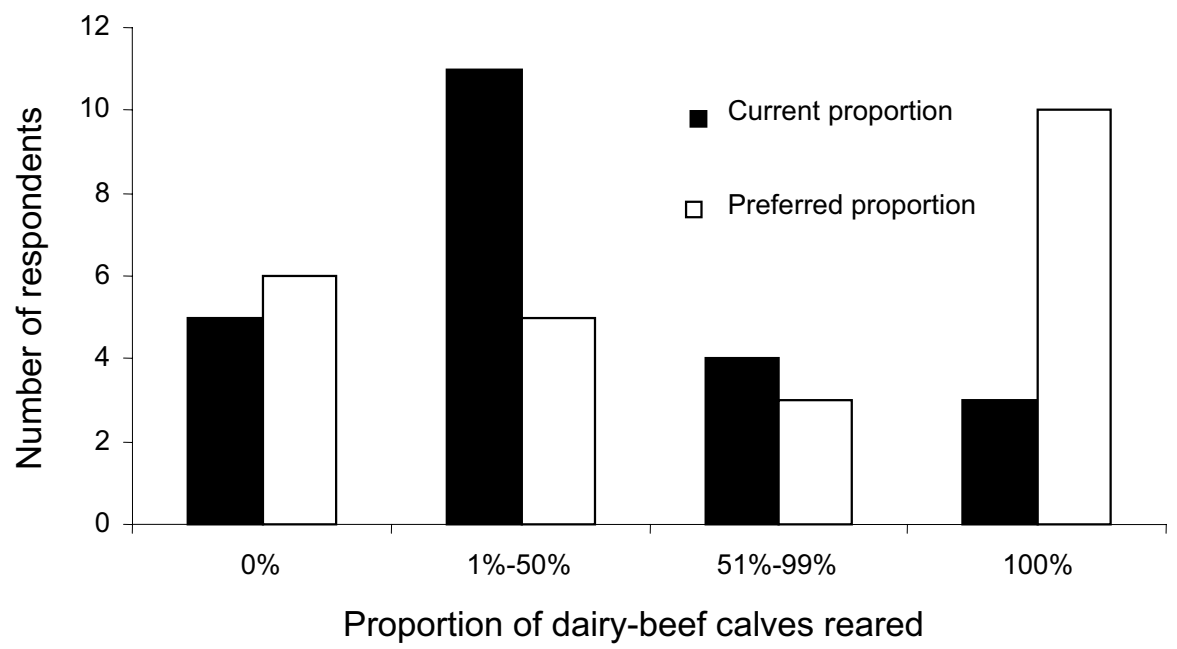

Figure 3 Criteria used by calf rearers to select 4-day-old calves.

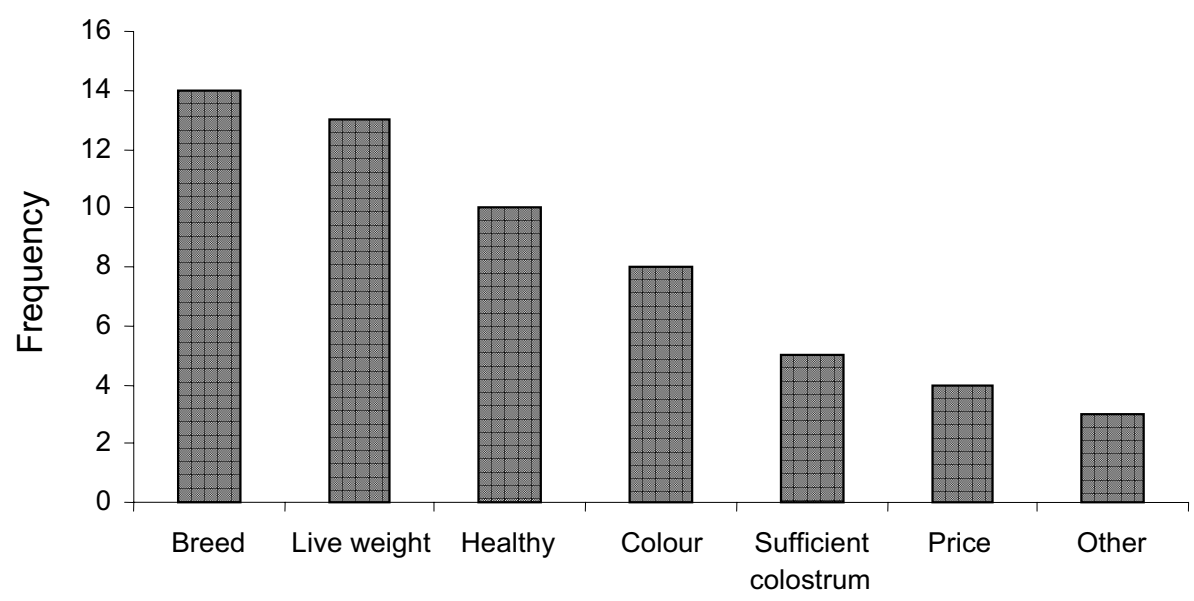

\section{Selection criteria for 4-day-old calves}

for importance (Table 1) and satisfaction (Table 2), 10 meaning highly important or completely satisfied. Ease of calving in their herd was considered the most important factor, followed by payment security for calves, producing a sufficient number of heifer replacements and minimising the total cost of mating. Of least importance were having a binding contract with a calf buyer, mating the herd with short gestation bulls and 
Table 3 Level of importance calf rearers place on factors related to calf purchase, sales and performance.

\begin{tabular}{lccc}
\hline Question & Mean & SD & $\mathbf{n}$ \\
\hline Weaner calf price & 9.3 & 1.1 & 17 \\
Payment security for weaner calves & 9.1 & 1.3 & 17 \\
Sourcing high quality calves & 8.8 & 1.2 & 22 \\
Calves growing rapidly after weaning & 8.8 & 1.2 & 22 \\
Gross margin on weaned calves & 8.5 & 2.1 & 17 \\
Calf growth rate during rearing & 8.4 & 1.5 & 23 \\
Certainty of weaner calf price & 8.4 & 1.5 & 17 \\
Long-term relationships with dairy farmers & 8.4 & 1.7 & 22 \\
Certainty of selling weaner calves & 8.1 & 1.6 & 20 \\
Four-day-old calf price & 8.0 & 1.9 & 20 \\
Long-term relationships with beef finishers & 7.5 & 2.2 & 17 \\
Certainty of 4-day-old calf price & 7.3 & 2.3 & 21 \\
Receiving a premium for dairy-beef weaners & 7.1 & 3.0 & 17 \\
Having a binding contract with a finisher & 6.5 & 2.3 & 17 \\
Flexibility to sell weaner calves on spot market & 6.1 & 2.2 & 19 \\
Having a binding contract with a dairy farmer & 5.8 & 2.6 & 22 \\
Flexibility to buy 4-day-old calves on spot market & 5.5 & 2.2 & 21 \\
\hline
\end{tabular}

Table 4 Level of satisfaction calf rearers derive from factors relating to buying and selling calves.

\begin{tabular}{lccc}
\hline Question & Mean & SD & $\mathbf{n}$ \\
\hline Payment security offered by your main calf buyer & 8.5 & 2.0 & 15 \\
That your calves grow rapidly after weaning & 7.9 & 2.0 & 21 \\
With calf growth rates you currently achieve & 7.6 & 1.7 & 23 \\
Ability to sell calves with certainty when you want & 7.4 & 2.2 & 20 \\
Relationships you have with dairy farmers for buying calves & 7.0 & 2.7 & 20 \\
Ability to source high quality 4-day-old calves & 6.8 & 2.2 & 20 \\
Relationships you have with beef finishers for selling weaner calves & 6.6 & 2.6 & 11 \\
\hline
\end{tabular}

Figure 4 Percentage of dairy-beef cattle finished by respondents to the cattle finishers survey, $n=44$.

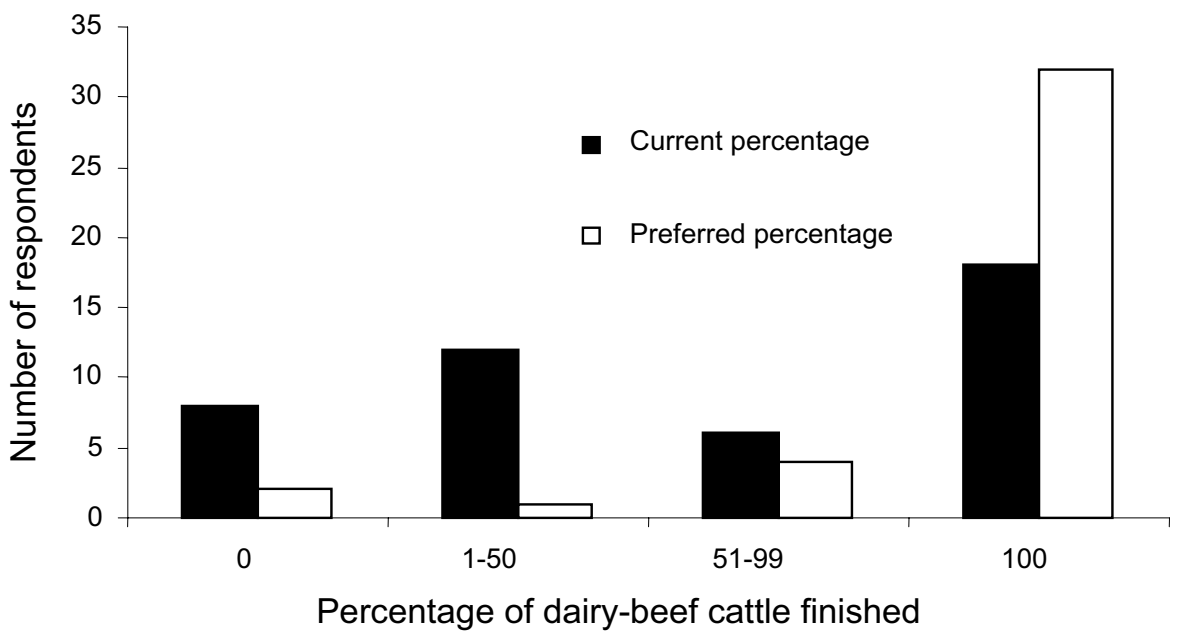

being able to buy bulls that will produce calves with a high growth rate. Respondents felt greatest satisfaction with the payment security offered by their main calf buyer, followed by ease of calving and producing sufficient herd replacements. They were least satisfied with the availability of beef sires that are performance recorded for calving ease and their current mating costs.

\section{Calf rearer survey}

Most survey respondents were rearing fewer than 50\% dairy-beef calves (the balance being Friesian bulls), but most respondents would prefer to rear more dairy-beef calves. Nearly half those surveyed said they would prefer to rear only dairy-beef calves (Figure 2). Breed, live weight, general health, colour and sufficient colostrum 
Figure 5 Selection criteria used by cattle finishing farmers to purchase weaner calves.

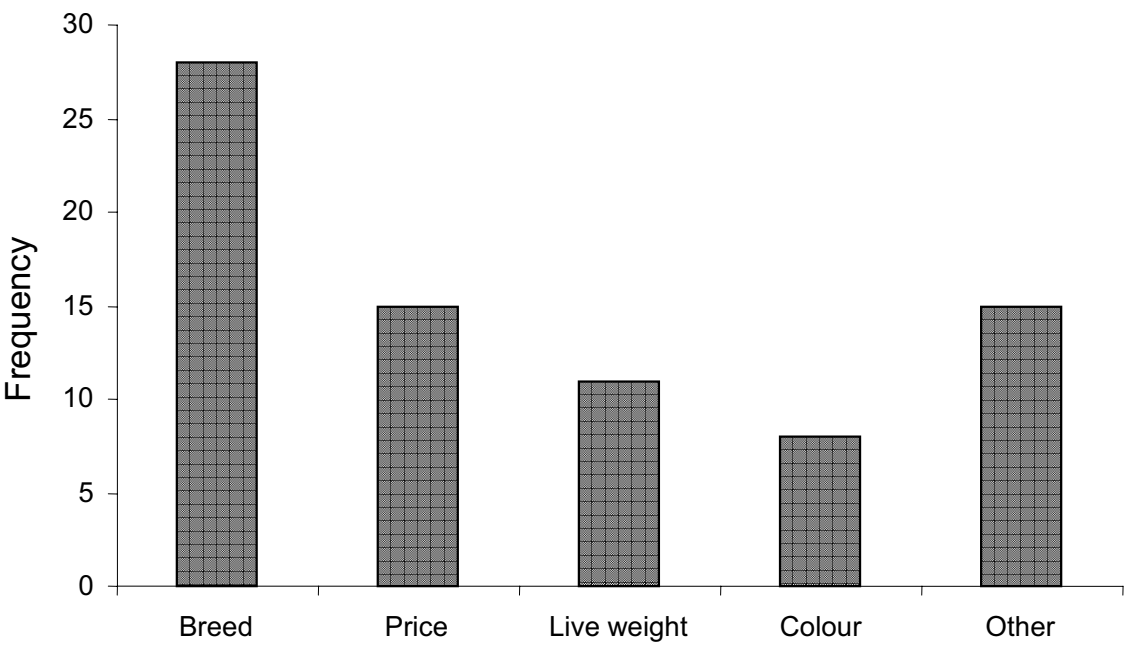

Weaner selection criteria

Table 5 Level of importance beef finishing farmers have with factors related to weaner calf purchase, cattle sales, and cattle performance.

\begin{tabular}{lccc}
\hline Question & Mean & SD & $\mathbf{n}$ \\
\hline Payment security for finished cattle & 9.4 & 1.0 & 44 \\
The price you receive for finished cattle & 9.4 & 1.2 & 44 \\
Certainty that you can sell your finished cattle when you want to & 9.1 & 1.0 & 44 \\
The gross margin on finished cattle & 9.0 & 1.1 & 44 \\
Growth rate during finishing & 8.7 & 1.2 & 44 \\
The cattle you finish produce a high meat yield & 8.7 & 1.2 & 43 \\
Certainty in sale price for finished cattle & 8.5 & 1.4 & 44 \\
Being able to source high quality calves when you want them & 8.4 & 2.0 & 42 \\
The flexibility to sell finished cattle on the spot market if higher prices are available & 8.2 & 1.5 & 44 \\
Finishing your cattle before the second winter & 8.2 & 2.5 & 44 \\
Having a long term relationship with a beef processor for selling finished cattle & 7.6 & 2.4 & 44 \\
The price you pay rearers for weaner calves & 7.5 & 2.2 & 30 \\
Certainty of purchase price for weaner calves & 7.3 & 2.2 & 30 \\
The flexibility to buy weaner calves on the spot market if lower prices are available & 7.2 & 2.4 & 31 \\
Having a long term relationship with a rearer for sourcing calves & 7.2 & 2.5 & 38 \\
Receiving a premium for dairy-beef cattle over Friesian bulls & 6.0 & 2.4 & 42 \\
Having a binding contract with a rearer & 5.8 & 2.8 & 35 \\
Having a binding contract with a meat processor & 5.7 & 2.5 & 41 \\
\hline
\end{tabular}

Table 6 Level of satisfaction beef finishing farmers have with factors relating to weaner calf purchase, cattle sales, and cattle performance.

\begin{tabular}{lccc}
\hline Question & Mean & SD & n \\
\hline Payment security offered by your main meat processor & 8.1 & 1.9 & 44 \\
Relationships you have with your meat processor for selling finished cattle & 8.0 & 1.8 & 44 \\
Certainty that you can sell your finished cattle when you want to & 7.9 & 1.8 & 44 \\
That the cattle you finish produce a high meat yield & 7.7 & 1.6 & 44 \\
Proportion of cattle you finish before their second winter & 7.6 & 2.1 & 43 \\
Cattle growth rates you currently achieve & 7.5 & 1.1 & 44 \\
Relationships you have with rearers for sourcing cattle & 7.1 & 2.4 & 31 \\
Ability to source high quality weaner calves & 6.8 & 2.1 & 28 \\
\hline
\end{tabular}


were all used more commonly than price as criteria for selecting 4-day-old calves (Figure 3).

Respondents were asked to rate a series of factors relating to calf purchases, sales and performance on a scale of 1-10 for importance (Table 3) and satisfaction (Table 4), 10 meaning highly important or completely satisfied. The factor they placed most importance on was weaner calf price, followed by payment security for weaner calves, being able to source high quality calves and that the calves they rear grow rapidly after weaning. Of least importance was having the flexibility to buy 4day-old calves on the spot market and having a binding contract with a dairy farmer. They w ere most satisfied with payment security for weaner calves and least satisfied with the relationships they have with finishers for selling weaners and the ability to source high quality 4-day-old calves.

\section{Finishing farmer survey}

Approximately half of the farmers surveyed finished at least $50 \%$ dairy-beef cattle (the balance being beef breeds or Friesian bulls) (Figure 4). However, approximately $75 \%$ of those same farmers said that they would prefer to finish only dairy-beef cattle, and most of the farmers who are not currently finishing any dairy-beef cattle would like to finish at least some. This suggests that finishers are unable to source sufficient dairy-beef cattle.

Breed was almost twice as frequently cited as a selection criterion when purchasing weaner cattle than any other (Figure 5). Price was important to approximately one-third of respondents. This is a similar pattern to that expressed by calf rearers, although liveweight appears less important for finishers.

Only $15 \%$ of respondents said they pay a premium for dairy-beef weaner bull calves over their Friesian bull counter parts, yet $35 \%$ indicated it would be fair to pay a premium of $\$ 30 /$ hd or more. Forty percent of respondents receive a premium for finished dairy-beef steers and bulls over Friesian bulls. This premium ranged between 5 and $20 \mathrm{c} / \mathrm{kg}$ of carcass weight. When comparing finished dairy-beef heifers to Friesian bulls, $85 \%$ indicated there was no premium, however, $65 \%$ indicated that a fair premium for the heifers would be between 10 and $50 \mathrm{c} / \mathrm{kg}$ of carcass weight.

Respondents were asked to rate a series of factors relating to calf purchases, cattle sales and cattle performance on a scale of 1-10 for importance (Table 5) and sa tisfaction (Table 6), 10 meaning highly important or completely satisfied. Of greatest importance to finishers was payment security for finished cattle, price received for finished cattle and the certainty that they can sell cattle when they want to. Of least importance was having a binding contract with either the calf rearer or meat processor and having a long-term relationship with a rearer for sourcing calves. They were most satisfied with the relationship they have with their meat processor and the payment security they provide. They were least satisfied with their ability to source high quality weaner calves.

\section{Discussion}

The use of beef semen for AI in dairy herds is low when measured in total inseminations. Those dairy farmers using beef semen (36\%) are principally using it over low producing and low BW cows from which they do not desire a herd replacement. The remaining farmers, who do not use beef semen even for this purpose, represent an opportunity to produce more early-born ${ }^{2}$ dairy-beef calves. Rearers and finishers both indicated a demand for more good quality beef-cross calves. Thus, a premium should be available for dairy farmers supplying these calves. Two barriers restricting dairy farmers using beef semen are that $80 \%$ of dairy farmers indicated that natural mating was their preferred means of using beef genetics and $70 \%$ of dairy farmers believed that AI with beef semen would cause greater calving difficulty than with dairy semen. If beef semen were positioned as a less expensive alternative this may improve its adoption because dairy farmers strongly indicated that minimising the cost of mating was important.

Almost a quarter of dairy farmers were not using beef bulls for follow-up mating after AI. The initial farmer interviews indicated that some reasons for this are that farmers of Jersey herds seldom use beef bulls because the resultant calves are perceived to be of low value regardless of the breed of the sire and the purchase price of quality beef bulls may inhibit others, given that an alternative is to lease low quality bulls for as little as $\$ 400 / \mathrm{hd}$ for the mating season without the responsibility of ownership. Over $40 \%$ of respondents were mating between $10-30 \%$ of their herd to beef bulls. However, the genetic potential these bulls provide to the beef industry is unknown. Breed and calving ease were clearly the main criteria used in selecting bulls, followed by price and, unfortunately too often, no criteria at all.

Approximately $70 \%$ of dairy farmers indicated that a premium of $\$ 30 /$ hd for 4 -day-old calves would encourage them to AI with beef semen rather than natural mate with unrecorded bulls. Thus, the issue of calving difficulty needs to be clarified, and data on calving ease needs to be made available for both AI and naturally-mated sires. All downstream participants expressed demand for good quality dairy-beef cattle,

\footnotetext{
${ }^{2}$ Earlier born calves are in greater demand by cattle finishers and subsequently, calf rearers.
} 
and preparedness to pay a $\$ 30-50$ premium for such cattle. Therefore, the potential profit for dairy farmers through using quality beef genetics should be emphasised.

In general both rearers and finishers displayed a desire to farm a greater proportion of dairy-beef cross cattle, indicating a supply and demand imbalance in the industry. Calf rearers strongly indicated that breed, liveweight, and general calf health were the most important selection criteria when buying calves. Price was the least cited of the six selection criteria, which demonstrates that rearers are prepared to pay for quality, and indicates that quality will be reflected in sale price. Factors which both of these categories of farmer placed greatest importance on was payment security (also highly satisfied) and the price received for their finished product. Both felt least satisfaction with the ability to source high quality cattle and their relationship with each other for buying and selling cattle. Interestingly, they both placed a low level of importance on long-term relationships or binding contracts with one another.

Breed was the most common criterion used by finishers when selecting weaners for purchase, being almost two times more important than price or live weight. This emphasis on breed indicates that finishers believe they know the potential performance of the cattle by breed. The reduced emphasis on live weight may be because most calves available are of a similar weight, and $100 \mathrm{~kg}$ has been set by the industry as an acceptable 'bar' that must be met. Finishers rated the ability to source high-quality weaner calves more important than the price paid for those calves or the certainty of their purchase price. Rearers considered calf growth after weaning to be important, indicating that their reputation with finishers ranks highly, but seem unprepared to build relationships around this.

\section{Conclusions}

Dairy farmers make the most critical decisions regarding the genetic make-up of most of the cattle entering the NZ beef industry. Therefore, other participants in the beef value chain must recognise dairy farmers as partners in the industry and provide them with information and solutions targeted at benefiting dairy farmers. Calf production, both number and genetics play critical roles in this value chain. Many dairy farmers see calf production as a by-product of a milk production system, and thus are primarily interested in controlling their herd mating costs and maintaining the health of their herd, i.e. calving ease. Any strategy to increase the production of dairy-beef calves must address these concerns.

There is a need for co-ordination and leadership from within the dairy-beef industry to effect change. At present there are insufficient incentives for dairy farmers to change their herd mating practices; therefore, those further along the value chain must re-evaluate the incentives for dairy farmers to use beef genetics across their herd. Encouraging this change in farmer behaviour will probably require higher prices for dairy-beef calves (\$30-50/calf is acceptable to most dairy farmers) and reduced mating costs (which can be achieved through the provision of beef semen and beef sires).

Rearers are not in a strong position to offer these incentives to dairy farmers, because they are predominantly margin takers. Therefore, this responsibility falls on either beef finishers or meat processors. To date, processor s have been unwilling to pay farmers on a yield-related basis and reward those producing the cattle of the greatest value to them. A revision of this pricing policy would undoubtedly result in a change in beef finisher behaviour, with a shift from focusing on beef production per hectare to the quality and value of beef produced/ha, and therefore an even greater demand for dairy-beef cross cattle.

Processors have also been reluctant, and will probably continue to be reluctant to offer long-term price contracts for the supply of finished cattle. They see the timeframe from conception of the calf to sale of the meat product (minimum 27 months) as increasing their risk to an unacceptable level. This leaves finishers, by default, in the best position to co-ordinate and lead change within their value chain through closer relationships with both dairy farmers and calf rearers. Finishers could also rely upon large-scale calf rearers to maintain relationships with dairy farmers. Finishers should consider how to identify good-quality beef genetics that are well suited to dairy systems and provide these genetics to dairy farmers in return for a supply of the resulting dairy-beef calves. These calves could be contract reared, removing uncertainty and cost for rearers, before being finished by the beef finishers.

\section{ACKNOWLEDGEMENTS}

This project was undertaken as part of a research programme funded by Meat and Wool New Zealand in the area of developing sustainable and profitable beef production systems. Dairy Insight also contributed funding to this particular project. Thank you to the mentor group for assisting in guiding the research and interpreting the findings.

\section{REFERENCES}

Beeby, N. 2003. The World of Beef and its Markets. Ed. D.C. Smeaton. Profitable Beef Production: 1-13.

McDermott, A.; Smeaton, D.; Sheath, G.; Dooley, L. 2005. A model of the New Zealand beef value chain: evaluating opportunities. Proceedings of the New Zealand Grassland Association 67: 81-86. 